\title{
Germanium Extraction from Sulfuric Acid Solutions in the Presence of Thiocyanate Ion
}

\author{
Natalya A. Grigorieva*a, \\ Gani K. Kulmuchamedov ${ }^{\mathrm{b}}$ and Isaak Yu. Fleitlikh ${ }^{\mathrm{a}}$ \\ ${ }^{a}$ Institute of Chemistry and Chemical Technology SB RAS \\ FRC "Krasnoyarsk Science Center SB RAS" \\ Krasnoyarsk, Russian Federation \\ ${ }^{b}$ Northern Katpar LLC \\ Karaganda, Kazakhstan
}

Received 11.10.2020, received in revised form 10.11.2020, accepted 03.12.2020

Abstract. The extraction of Ge (IV) from sulfuric acid solutions in the presence of thiocyanate ion with various extractants (caprylic, poly(2-ethylhexyl)phosphonitrile, bis(2,4,4-trimethylpentyl) dithiophosphinic acids, trialkylmethylammonium thiocyanate, etc.) has been studied. In all cases, the thiocyanate ion increases germanium extraction as compared to the extraction from sulfuric acid solutions.

During the germanium extraction with bis(2,4,4-trimethylpentyl)dithiophosphinic acid (Cyanex 301, HR), a significant increase in the germanium extraction is due to the formation of a cationic intracomplex compound of the composition $\left[\mathrm{Ge}(\mathrm{OH})_{3-n} \mathrm{R}_{n}\right]^{+}\left[\mathrm{HSO}_{4}\right]$, where $\mathrm{n}=1-3$. Due to the large synergistic effect for the extraction of $\mathrm{Ge}$, it is possible to use an extractant with a concentration of $0.1-0.15 \mathrm{~mol} / 1$.

Trialkylmethylammonium thiocyanate (TAMAR), also shows a high efficiency of germanium extraction from sulfate thiocyanate solutions. For 5-6 stages of extraction with a $0.5 \mathrm{M}$ solution of TAMAP, the extraction of Ge was $99.5 \%$. The composition of the extracted complex supposedly corresponds to $\left(\mathrm{R}_{4} \mathrm{~N}\right)_{2}\left[\mathrm{Ge}(\mathrm{CNS})_{6}\right]$.

The use of extraction systems based on Cyanex 301 and TAMAR in the presence of thiocyanate ion significantly reduces the concentration of extractants and is of undoubted practical interest for hydrometallurgical processes for the germanium extraction.

Keywords: solvent extraction, germanium, Cyanex 301, trialkylmethylammonium thiocyanate, thiocyanate ion, synergistic effect.

(c) Siberian Federal University. All rights reserved

This work is licensed under a Creative Commons Attribution-NonCommercial 4.0 International License (CC BY-NC 4.0).

* Corresponding author E-mail address: natasha@icct.ru 
Citation: Grigorieva N.A., Kulmuchamedov G.K., Fleitlikh I.Yu. Germanium extraction from sulfuric acid solutions in the presence of thiocyanate ion, J. Sib. Fed. Univ. Chem., 2020, 13(4), 542-552. DOI: 10.17516/1998-2836-0204

\title{
Экстракция германия из сернокислых растворов в присутствии роданид-иона
}

\author{
Н.А. Григорьева ${ }^{a}$, \\ Г.К. Кулмухамедов ${ }^{\tilde{\sigma}}$ И.Ю. Флейтлих ${ }^{\mathrm{a}}$ \\ ${ }^{a}$ Институт химии и химической технологии \\ ФИЦ «Красноярский научный иентр СО РАН» \\ Российская Федерачия, Красноярск \\ ${ }^{6} \mathrm{TOO} \mathrm{«Северньий} \mathrm{Катпар»}$ \\ Караганда, Казахстан
}

Аннотащия. Исследована экстракция Ge (IV) из сернокислых растворов в присутствии роданид-иона различными экстрагентами (каприловой, поли(2-этилгексил)фосфонитрильной, бис $(2,4,4$-триметилпентил)дитиофосфиновой кислотами, триалкилметиламмоний роданидом и др.). Во всех случаях роданид-ион увеличивает экстракцию Ge по сравнению с экстракцией из сернокислых растворов.

При экстракции германия бис(2,4,4-триметилпентил)дитиофосфиновой кислотой (Cyanex 301, HR) значительное возрастание извлечения германия обусловлено образованием катионного внутрикомплексного соединения состава: $\left[\mathrm{Ge}(\mathrm{OH})_{3-\mathrm{n}} \mathrm{R}_{\mathrm{n}}\right]^{+}\left[\mathrm{HSO}_{4}\right]$, где $\mathrm{n}=1-3$. В связи с большим синергетическим эффектом для извлечения $\mathrm{Ge}$ возможно использование экстрагента $\mathrm{c}$ концентрацией 0,1-0,15 моль/л.

Триалкилметиламмоний роданид (ТАМАР) также показывает достаточно высокую эффективность извлечения $\mathrm{Ge}$ из сернокислых роданидных растворов. За 5-6 ступеней экстракции 0,5 М раствором ТАМАР в растворителе извлечение $\mathrm{Ge}$ равнялось 99,5 \%. Состав экстрагируемого комплекса предположительно соответствует формуле $\left(\mathrm{R}_{4} \mathrm{~N}\right)_{2}\left[\mathrm{Ge}(\mathrm{CNS})_{6}\right]$.

Использование экстракционных систем на основе Суanex 301 и ТАМАР в присутствии роданидиона существенно уменьшает концентрацию экстрагентов и представляет несомненный практический интерес для гидрометаллургических процессов извлечения германия.

Ключевые слова: жидкостная экстракция, германий, Суanex 301, ТАМАР, роданид-ион, синергетический эффект.

Цитирование: Григорьева, Н.А. Экстракция германия из сернокислых растворов в присутствии роданид-иона / Н.А. Григорьева, Г.К. Кулмухамедов, И.Ю. Флейтлих // Журн. Сиб. федер. ун-та. Химия, 2020. 13(4). С. $542-552$. DOI: $10.17516 / 1998-2836-0204$ 


\section{Введение}

Германий широко используется в полупроводниках, оптоволоконной технике, катализе и т.д., однако природные ресурсы этого элемента невелики [1]. Более половины германия производится из вторичных источников, в цинковых и угольных отраслях германий может производиться как побочный продукт [2]. Поэтому разработка высокоэффективных процессов выделения германия крайне важна. Известные методы выделения германия из растворов, в частности из сернокислых, основанные на осаждении малорастворимых соединений Ge с танином, сульфидов или цементации на металлическом цинке, а также сорбцией достаточно сложны и имеют существенные недостатки [3]. В связи с этим экстракционные методы извлечения германия представляют большой интерес.

Первым промышленно известным экстрагентом для германия был $\alpha$-гидроксиоксим Lix 63 [5,8-диэтил-7-гидроксидодекан-6-оксим, HA]. Однако для эффективной экстракции германия требовалась высокая концентрация экстрагента и кислотность водного раствора. Состав экстрагируемых комплексов соответствует формулам $\mathrm{Ge}(\mathrm{OH})_{3} \mathrm{~A}$ и $\mathrm{Ge}(\mathrm{OH}) \mathrm{A}_{2}\left(\mathrm{HSO}_{4}\right)$ [4]. Добавление к Lix 63 фосфорорганических кислот - октилфенилфосфорной (OPAP) [4] или 2-этилгексилового эфира 2-этилгексилфосфоновой кислоты [5] - приводит к синергетическому эффекту, что позволяет снизить концентрацию Lix 63. Состав экстрагируемых смешанных комплексов с ОРАР идентифицирован как $\mathrm{Ge}(\mathrm{OH})_{2} \mathrm{DA}$ и $\mathrm{GeDA}_{2}\left(\mathrm{HSO}_{4}\right)$ (где $\mathrm{D}$ - диалкильная форма ОРАР). Позже выдвинуты оксимы и другого строения, в частности HBL101 [6].

Смесь экстрагентов предложена при экстракции германия гидроксамовой кислотой (HGS98), где в качестве синергиста используется ди(2-этилгексил)фосфорная кислота (Д2ЭГФК) [7]. Недостаток способа - невысокая химическая устойчивость гидроксамовой кислоты.

Наиболее эффективным экстрагентом является Kelex 100 [7-(4-этил-1-метилоктил)-8хинолин, то же, что и Lix 26], он показал высокий уровень экстракции наряду с высокой селективностью. Германий хорошо извлекается этим экстрагентом в кислой области (при $\mathrm{pH} \leq 0$ ). Состав экстрагируемого соединения отвечает формуле $\left[\mathrm{GeL}_{3}\right]^{+}\left[\mathrm{HSO}_{4}\right][8]$. Экстракция $\mathrm{Ge} \mathrm{c}$ Кеlех в большинстве случаев замедлена [9].

Наряду с вышерассмотренными экстрагентами определенный интерес представляет Cyanex 301 [бис(2,4,4-триметилпентил)дитиофосфиновая кислота, HR][10]. Следует отметить, что по своим экстракционным свойствам Суanex 301 уступает Lix 63 и Kelex 100 [4, 8]. Согласно [11], состав экстрагируемого комплекса германия с Cуanex 301 определяется формулой $\mathrm{GeR}_{4}$.

Кроме хелатообразующих экстрагентов исследовалась экстракция германия в присутствии комплексообразователей - оксикислот: щавелевой $[12,13]$ или винной $[13,14]$. В качестве экстрагента использовали три(октилдецил)амин [12] или триалкилфосфиноксид (Суanex 923) [13], а также органические амины различного строения и фосфиноксид [14]. При сопоставимых условиях эффективность экстракции германия изменялась в следующем порядке: Аликват $336>$ Аламин $336>$ Суаnex 923 [14]. Изученные системы оказались вполне эффективны при извлечении германия, к тому же их характеризует относительно быстрая кинетика, для достижения равновесия достаточно 3-5 мин контакта фаз. К некоторым недостаткам этих систем можно отнести высокий расход комплексообразователя и проблемы с селективностью, например, при отделении от мышьяка [14]. 
Из представленного обзора можно сделать вывод, что круг эффективных экстрагентов для германия ограничен, это Kelex 100, Lix 63 и органические амины в присутствии оксикислот. К тому же такие экстрагенты, как Kelex 100 и Lix 63, достаточно дороги.

Ранее было показано, что экстракция германия Kelex 100 и Lix 63 из сернокислых растворов в присутствии роданид-иона существенно возрастает [15]. Представляется целесообразным рассмотреть влияние роданид-иона на экстракцию $\mathrm{Ge}$ с более широким кругом экстрагентов, на что направлены настоящие исследования.

\section{Экспериментальная часть}

\section{Исходные вещества}

В качестве экстрагентов использованы реагенты, представленные в табл. 1.

Экстрагенты, кроме Д2ЭГФК, ТАМАС, ТАА, и разбавители использовали без предварительной обработки. Техническая Д2ЭГФК, содержащая 68 \% основного вещества, отмывалась от моноалкилфосфорных кислот раствором $\mathrm{NaOH}$ (1,0 моль/л) на трех ступенях. Очищенный продукт содержал 90 \% Д2ЭГФК. ТАМАС и ТАА переводили в роданидную форму контактированием с раствором роданида аммония с концентрацией 1,0 моль/л на двух и одной ступенях соответственно.

В качестве растворителя использовали керосин $\left(\mathrm{C}_{10} \mathrm{H}_{22}\right.$, ТУ 38-101-454-74) производства ЗАО «СП «Химпром», смесь керосина с 20 \% 2-этилгексанолом (основного вещества 99,0 \%) производства ОАО «Газпромнефтехим», а также толуол (основного вещества 99,85 \%) производства ООО «Компонент-Реактив» (все Россия).

Таблица 1. Характеристика экстрагентов

Table 1. Characteristics of extractants

\begin{tabular}{|c|c|c|c|c|c|}
\hline № & \multicolumn{2}{|l|}{ Экстрагенты } & $\begin{array}{c}\% \\
\text { основного }\end{array}$ & Фирма-производитель & Страна \\
\hline 1 & каприловая кислота & К.К. & 98 & SigmaAldrich & США \\
\hline 2 & неодекановая кислота & Versatic 10 & 95 & Hexion & США \\
\hline 3 & 1-фенил-1,3 декандион & Lix 54 & 95 & Cognis & США \\
\hline 4 & $\begin{array}{l}\text { бис(2,4,4-триметилпентил)- } \\
\text { дитиофосфиновая кислота }\end{array}$ & Cyanex 301 & 80 & CYTEC & Канада \\
\hline 5 & $\begin{array}{l}\text { бис(2,4,4-триметилпентил)- } \\
\text { фосфиновая кислота }\end{array}$ & Cyanex 272 & 85 & CYTEC & Канада \\
\hline 6 & $\begin{array}{l}\text { ди(2-этилгексил) фосфорная } \\
\text { кислота }\end{array}$ & Д2ЭГФК & 90 & $\begin{array}{c}\text { ООО «Волго- } \\
\text { градпромпроект» }\end{array}$ & Россия \\
\hline 7 & $\begin{array}{l}\text { поли(2-этилгексил)фосфо- } \\
\text { нитрильная кислота }\end{array}$ & П2ЭГФНК & 90 & АО «ВНИИХТ» & Россия \\
\hline 8 & $\begin{array}{l}\text { триалкилметиламмоний сульфат; } \\
\left(\mathrm{R}_{3} \mathrm{NCH}_{3}\right)_{2} \mathrm{SO}_{4}, \\
\text { где } \mathrm{R} \text { алкил }-\mathrm{C}_{7}-\mathrm{C}_{9}\end{array}$ & TAMAC & 63,7 & $\begin{array}{l}\text { АО «Институт } \\
\text { Гидроцветмет» }\end{array}$ & Россия \\
\hline 9 & $\begin{array}{l}\text { Триалкиламин } \\
\text { где } \mathrm{R} \text { алкил }-\mathrm{C}_{7}-\mathrm{C}_{9}\end{array}$ & TAA & 85 & $\begin{array}{c}\text { ОАО } \\
\text { «Гидрометаллургический } \\
\text { завод» }\end{array}$ & Россия \\
\hline
\end{tabular}


Растворы германия готовили растворением порошка германия $(99,999$ \%, производитель $\mathrm{AO}$ «Германий», Россия) в $0,1 \mathrm{M} \mathrm{NH}_{4} \mathrm{OH}+0,5 \mathrm{MH}_{2} \mathrm{O}_{2}$. В дальнейшем необходимые концентрации германия и серной кислоты достигались разбавлением головного раствора (1 г/л Ge в 1,0 M $\mathrm{H}_{2} \mathrm{SO}_{4}$ ) дистиллированной водой или добавлением серной кислоты. Соли и кислоты были квалификации «химически чистый» или «чистый для анализа».

\section{Методика эксперимента}

Опыты по экстракции и реэкстракции проводили путем механического перемешивания в пробирках или делительных воронках при температуре $22-25^{\circ} \mathrm{C}$.

Время контакта фаз при экстракции с Суanex 301 составляло 2,0 ч, для ТАМАC - 5-10 мин. Отношение объемов водной и органической фаз (О:В) равнялось 1:1.

Регулировку $\mathrm{pH}$ осуществляли введением в водную фазу различных количеств $\mathrm{NaOH}$ или $\mathrm{H}_{2} \mathrm{SO}_{4}$. Значения $\mathrm{pH}$ определяли при помощи стеклянного электрода. Использовали $p H$-метр Аквилон рН-410.

Определение германия в водных фазах проводили колориметрически с фенилфлуороном. Относительная погрешность определения германия составляла менее $1 \%$. Содержание в органической фазе находили по разности между исходным раствором и конечной водной фазой. Определение роданид-иона осуществляли с помощью азотнокислого серебра по методу Фольгарда [16].

\section{Результаты и обсуждение}

Ранее было показано [10], что степень извлечения германия из сернокислых растворов монокарбоновыми кислотами (Versatic 10), фосфорорганическими кислотами (Д2ЭГФК, Cуanex 272), третичными и четвертичными органическими аминами (Alamin 336, Aliquat 336) и некоторыми другими экстрагентами равна или близка к нулю. В табл. 2 приведены данные

Таблица 2. Экстракции германия из сернокислых растворов. Исходная водная фаза: $\mathrm{Ge}=0,185$ г/л; $\mathrm{NH}_{4} \mathrm{CNS}=1,0 \mathrm{M}$, растворитель: № 1-7 керосин; № 8 - толуол

Table 2. Germanium extraction from sulfuric acid solutions. Initial aqueousphase: $\mathrm{Ge}=0,185 \mathrm{~g} / 1 ; \mathrm{NH}_{4} \mathrm{CNS}=1,0 \mathrm{M}$, solvent: № 1-7 kerosene; № 8 - toluene

\begin{tabular}{|c|c|c|c|c|c|c|c|}
\hline \multirow{3}{*}{ № } & \multirow{3}{*}{$\begin{array}{c}\text { Экстрагент, } \\
\text { моль/л }\end{array}$} & \multicolumn{3}{|c|}{$\mathrm{H}_{2} \mathrm{SO}_{4}-0,25 \mathrm{M}$} & \multicolumn{3}{|c|}{$\mathrm{H}_{2} \mathrm{SO}_{4}-2,0 \mathrm{M}$} \\
\hline & & \multicolumn{2}{|c|}{ Концентрация Ge, г/л } & \multirow{2}{*}{$\varepsilon ; \%$} & \multicolumn{2}{|c|}{ Концентрация Ge, г/л } & \multirow{2}{*}{$\varepsilon ; \%$} \\
\hline & & Орг. фаза & Водн. фаза & & Орг. фаза & Водн. фаза & \\
\hline 1 & 1,0 K.K. & 0,035 & 0,15 & 18,9 & 0,037 & 0,148 & 20,0 \\
\hline 2 & 1,0 Versatic 10 & 0,025 & 0,16 & 13,5 & 0,035 & 0,15 & 18,9 \\
\hline 3 & 1,0 Lix 54 & 0,035 & 0,15 & 18,9 & 0,137 & 0,048 & 73,2 \\
\hline 4 & 0,1 Cyanex 301 & 0,095 & 0,09 & $51,3 *$ & 0,179 & 0,006 & 96,5 \\
\hline 5 & 0,5 Cyanex 272 & 0,035 & 0,15 & 18,9 & - & - & - \\
\hline 6 & 0,5 Д2ЭГФК & 0,015 & 0,17 & 8,1 & 0,05 & 0,135 & 27,0 \\
\hline 7 & 0,5 П2ЭГФНК & 0,065 & 0,12 & 35,1 & 0,147 & 0,038 & 79,5 \\
\hline 8 & 0,4 TAMAP & 0,037 & 0,148 & 20,0 & 0,155 & 0,03 & 83,8 \\
\hline
\end{tabular}

*В отсутствие роданида аммония извлечение германия составило 25,7 \%. 
по экстракции германия из сернокислых растворов различными экстрагентами, в том числе и указанными выше, в присутствии роданид-иона.

Как видно из данных табл. 2, извлечение германия имеет место во всех рассмотренных системах, причем в некоторых (№ 3, 4, 7 и 8) оно достаточно высокое. Очевидно, что это связано с образованием экстрагируемых соединений с вхождением роданид-иона в состав комплекса.

Системы с Суапех 301 и ТАМАР будут рассмотрены более подробно.

В работах по экстракции германия из сернокислых растворов с Суanex 301 (HR) отмечается, что для эффективного извлечения германия необходима высокая концентрация экстрагента $\sim 40 \%$ ( 0,88 моль/л) [10]. В единственной работе, где рассматривается состав экстрагируемого соединения Ge c Cуanex 301 [11], он представлен в виде GeR4. Этот состав предложен без какихлибо доказательств, по аналогии с экстракцией редкоземельных элементов этим экстрагентом, что абсолютно некорректно, и, на наш взгляд, является ошибочным (см. далее). Германий при экстракции хелатообразующими экстрагентами, к которым относится Суаnех 301, способен образовывать так называемые катионные внутрикомплексные соединения [16]. Заряженные катионные комплексы, в частности $\left[\mathrm{GeR}_{3}\right]^{+}$, могут экстрагироваться только в присутствии какого-либо аниона. При экстракции германия из растворов серной кислоты это сульфат- и бисульфат-ионы. По аналогии с извлечением Ge из сернокислых растворов с LIX 63 [4] и Kelex 100 [8] процесс экстракции германия с Суanex 301 может быть описан уравнением 1 в общем виде:

$$
\mathrm{Ge}(\mathrm{OH})_{4(\mathrm{~B})}+\mathrm{nHR}_{(\mathrm{o})}+\left[\mathrm{HSO}_{4}\right]_{(\mathrm{B})}^{-}+\mathrm{H}_{(\mathrm{B})}^{+} \leftrightarrow\left[\mathrm{Ge}(\mathrm{OH})_{3-\mathrm{n}} \mathrm{R}_{\mathrm{n}}\right]^{+}\left[\mathrm{HSO}_{4}\right]_{(\mathrm{o})}^{-}+(\mathrm{n}+1) \mathrm{H}_{2} \mathrm{O}
$$

где $\mathrm{n}=1-3$, а индексы (в) и (о) обозначают водную и органическую фазы соответственно.

На рис. 1 показано влияние серной кислоты (кр. 1) и роданида аммония (кр. 2) на экстракцию германия Cyanex 301.

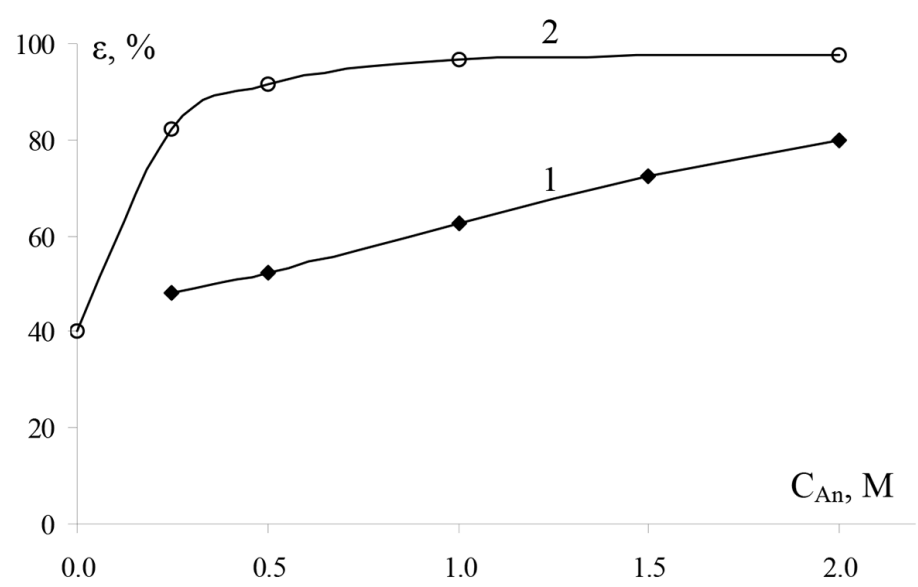

Рис. 1. Влияние серной кислоты и роданида аммония на экстракцию германия Суапех 301. Органическая фаза: Cуanex 301 в керосине; 1 - 0,5 M; 2 - 0,1 М. Водная фаза, M: Ge - 0,2 г/л (2,75 $\left.10^{-3} \mathrm{M}\right) .1-\mathrm{H}_{2} \mathrm{SO}_{4}$; $2-1,0 \mathrm{M} \mathrm{H}_{2} \mathrm{SO}_{4}+\mathrm{NH}_{4} \mathrm{CNS}$

Fig. 1. Effect of sulfuric acid and ammonium thiocyanate on the germanium extraction with Cyanex 301.Organic phase: Cyanex 301 in kerosene; $1-0,5 \mathrm{M} ; 2-0,1 \mathrm{M}$. Aqueous phase, M: Ge - $0.2 \mathrm{~g} / 1\left(2.75 \cdot 10^{-3} \mathrm{M}\right) .1-\mathrm{H}_{2} \mathrm{SO}$; $2-1.0 \mathrm{M} \mathrm{H}_{2} \mathrm{SO}_{4}+\mathrm{NH}_{4} \mathrm{CNS}$

$$
-547-
$$


Зависимость экстракции германия от концентрации $\mathrm{H}_{2} \mathrm{SO}_{4}$ имеет аномальный характер для катионообменных экстрагентов (кр. 1), т.е. извлечение германия возрастает с увеличением кислотности, что, очевидно, связано с уменьшением доли гидролизованных форм германия и возрастанием доли германия-катиона, а также концентрации иона $\left[\mathrm{HSO}_{4}\right]^{-}$, что согласно ур. 1 сдвигает реакцию вправо.

Введение в сернокислый раствор роданид-иона резко увеличивает извлечение германия (кр. 2). Уже при концентрации CNS, равной 0,25 моль/л, степень извлечения германия составила величину, близкую к 90,0 \% (86 \%). Очевидно, что роданид-ион входит в состав экстрагируемого соединения, а значительное возрастание экстракции $\mathrm{Ge}$, по-видимому, обусловлено более низкой степенью гидратации роданид-иона по сравнению с бисульфат-ионом $(\Delta \mathrm{G}=-61$ ккал/гион[CNS] и -87 ккал/Г-ион[ $\left.\mathrm{HSO}_{4}\right]^{-}$) и, соответственно, его лучшей экстрагируемостью [17]. Возрастание экстракции германия с увеличением концентрации $\mathrm{H}_{2} \mathrm{SO}_{4}$ и $\mathrm{NH}_{4} \mathrm{CNS}$ в водной фазе косвенно свидетельствует о вхождении бисульфат- и роданид-ионов в состав экстрагируемых соединений.

На рис. 2 представлена степень извлечения Ge из сернокислой (кр. 1) и сернокисло-роданистой (кр. 2) сред Суanex 301 различной концентрации.

Как и следовало ожидать, экстракция германия во втором случае проходит намного эффективней. Процесс экстракции германия с Суanex 301 из сернокислых растворов в присутствии роданида предположительно может быть описан уравнением 2 :

$$
\mathrm{Ge}(\mathrm{OH})_{4(\mathrm{~B})}+\mathrm{nHR}_{(\mathrm{o})}+[\mathrm{CNS}]_{(\mathrm{B})}^{-}+\mathrm{H}_{(\mathrm{B})}^{+} \leftrightarrow\left[\mathrm{Ge}(\mathrm{OH})_{3-\mathrm{n}} \mathrm{R}_{\mathrm{n}}\right]^{+}\left[\mathrm{CNS}^{-}{ }_{(\mathrm{o})}+(\mathrm{n}+1) \mathrm{H}_{2} \mathrm{O} .\right.
$$

Поскольку в присутствии роданид-иона экстракция германия из сернокислых растворов с Суаnex 301 проходит намного эффективнее, достаточно использовать экстрагент с концентрацией 0,1-0,15 моль/л.

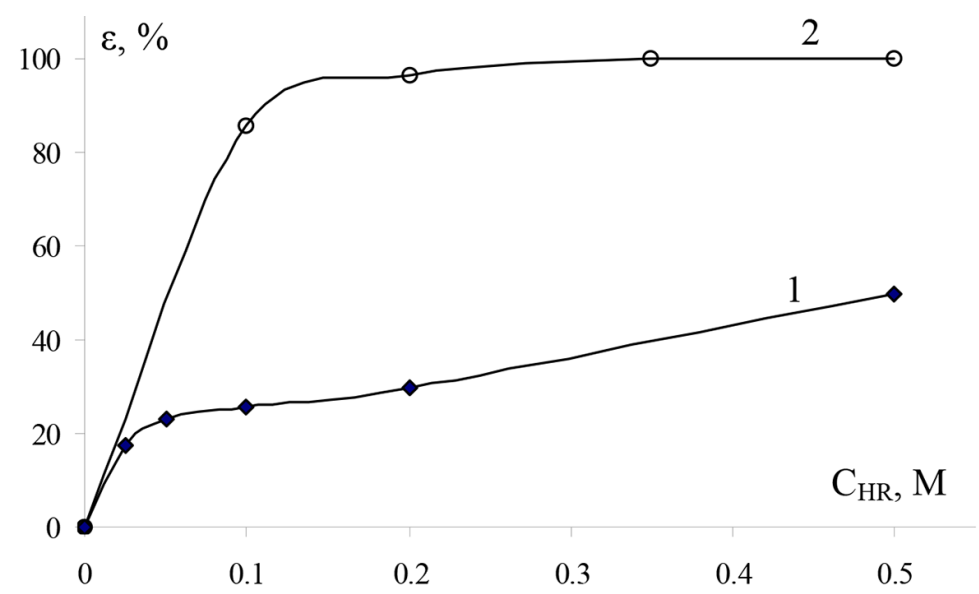

Рис. 2. Влияние концентрации Суапех 301 на извлечение германия из сернокислых растворов в отсутствие (1) и присутствии (2) роданид-иона. Органическая фаза: Суanex 301 в керосине. Водная фаза, M: Ge 0,2 глл $\left(2,75 \cdot 10^{-3} \mathrm{M}\right) .1-0,25 \mathrm{H}_{2} \mathrm{SO}_{4} ; 2-1,0 \mathrm{H}_{2} \mathrm{SO}_{4}+0,25 \mathrm{NH}_{4} \mathrm{CNS}$

Fig. 2. Effect of Cyanex 301 concentration on the germanium extraction from sulfuric acid solutions in the absence (1) and presence (2) of thiocyanate ion.Organic phase: Cyanex 301 in kerosene. Aqueous phase, $\mathrm{M}: \mathrm{Ge}-$ 0,2 глл $\left(2,75 \cdot 10^{-3} \mathrm{M}\right) .1-0,25 \mathrm{H}_{2} \mathrm{SO}_{4} ; 2-1,0 \mathrm{H}_{2} \mathrm{SO}_{4}+0,25 \mathrm{NH}_{4} \mathrm{CNS}$

$$
-548-
$$




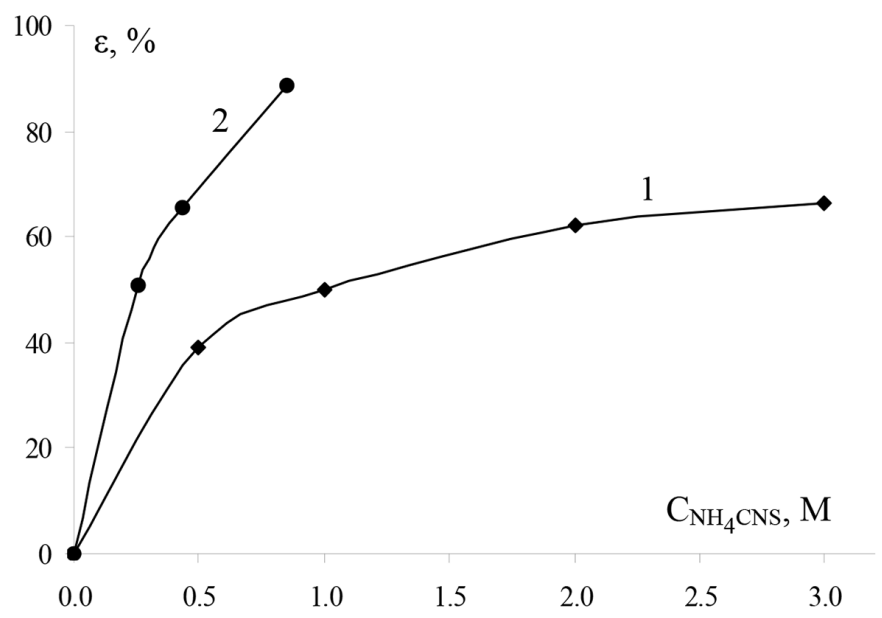

Рис. 3. Влияние роданида аммония на экстракцию германия ТАА и ТАМАР. Органическая фаза, разбавитель: керосин + 20 \% 2-этилгексанола; 1 - 0,4 M ТАA; 2 - 0,5 M ТАМАР. Водная фаза, M: 1 - Ge: 0,2 глл $\left(2,75 \cdot 10^{-3} \mathrm{M}\right)+0,25 \mathrm{M} \mathrm{H}_{2} \mathrm{SO}_{4}+\mathrm{NH}_{4} \mathrm{CNS}\left(\tau=5\right.$ мин); $2-\mathrm{Ge:} 0,14$ г/л $\left(1,93 \cdot 10^{-3} \mathrm{M}\right)+1,0 \mathrm{M} \mathrm{H}_{2} \mathrm{SO}_{4}+$ $\mathrm{NH}_{4} \mathrm{CNS}(\tau=5$ мин)

Fig. 3. Effect of ammonium thiocyanate on the germanium extraction with TAA and TAMAR: Organic phase, solvent: kerosene $+20 \%$ 2-ethylhexanol; 1 - 0,4 M TAA; 2 - 0,5 M TAMAR Aqueous phase, M: 1 - Ge: 0,2 g/1 $\left(2,75 \cdot 10^{-3} \mathrm{M}\right)+0,25 \mathrm{M} \mathrm{H}_{2} \mathrm{SO}_{4}+\mathrm{NH}_{4} \mathrm{CNS}(\tau=5 \mathrm{~min}), 2-\mathrm{Ge}: 0,14$ г/л $\left(1,93 \cdot 10^{-3} \mathrm{M}\right)+1,0 \mathrm{M} \mathrm{H}_{2} \mathrm{SO}_{4}+\mathrm{NH}_{4} \mathrm{CNS}$ $(\tau=5 \mathrm{~min})$

Экстракция анионных роданидных ацидокомплексов металлов ( $\mathrm{Zn}, \mathrm{Cd}, \mathrm{Co}$ и $\mathrm{Ni}$ ) солями органических аминов изучена и ранее [18]. Однако известна лишь одна работа по экстракции германия в присутствии роданид-иона с использованием протонированного диантипирилметана [19]. Авторы считают, что германий экстрагируется в виде гексароданогерманиевой кислоты. На рис. 3 представлены зависимости экстракции германия из сернокислых растворов TAА (кр. 1) и ТАМАР (кр. 2) от концентрации роданид-иона.

Видно, что ТАМАР извлекает германий заметно лучше, чем ТАА, при сравнительно невысоком содержании роданида (0,85 моль/л) извлечение германия составило около 90 \%.

Экстракцию германия ТАМАР (по аналогии с [19]) целесообразно рассматривать в две стадии: на первой - образование экстрагирующегося аниона (ур. 3)

$$
\mathrm{Ge}(\mathrm{OH})_{4(\mathrm{~B})}+6[\mathrm{CNS}]_{(\mathrm{B})}^{-}+4 \mathrm{H}_{(\mathrm{B})}^{+} \leftrightarrow\left[\mathrm{Ge}(\mathrm{CNS})_{6}\right]_{(\mathrm{B})}^{2-}+4 \mathrm{H}_{2} \mathrm{O},
$$

на второй - собственно анионообменная экстракция (ур. 4)

$$
2 \mathrm{R}_{4} \mathrm{NCNS}_{(\mathrm{o})}+\left[\mathrm{Ge}(\mathrm{CNS})_{6}\right]^{2-}{ }_{(\mathrm{B})} \leftrightarrow\left(\mathrm{R}_{4} \mathrm{~N}\right)_{2}\left[\mathrm{Ge}(\mathrm{CNS})_{6}\right]^{2-}{ }_{(\mathrm{o})}+2[\mathrm{CNS}]_{(\mathrm{B})}^{-}
$$

Реальная ситуация несколько сложнее, так как на процесс экстракции германия накладывается процесс экстракции роданистоводородной кислоты (ур. 5), (табл. 3).

$$
\mathrm{R}_{4} \mathrm{NCNS}_{(\mathrm{o})}+\mathrm{H}_{(\mathrm{B})}^{+}+[\mathrm{CNS}]_{(\mathrm{B})}^{-} \leftrightarrow \mathrm{R}_{4} \mathrm{NH}(\mathrm{CNS})_{2(\mathrm{o})} .
$$

Как видно из данных табл. 3, в молекулу экстрагента входят два роданид-иона, что подтверждают результаты [18], где также показано образование соединения $\mathrm{R}_{4} \mathrm{NH}(\mathrm{CNS})_{2}$. 
Таблица 3. Экстракции германия ТАМАР в зависимости от концентрации роданида. Экстрагент: 0,5 M TAMAР в керосине $+20 \%$ 2-этилгексанола; $[\mathrm{CNS}]_{(\text {o) }}=0,92 \mathrm{~N}$. Водная фаза: $1,93 \cdot 10^{-3} \mathrm{M} \mathrm{Ge}+1,0 \mathrm{M} \mathrm{H}_{2} \mathrm{SO}_{4}$ $+\mathrm{NH}_{4} \mathrm{CNS}$. Условия экстракции: $\mathrm{O}: \mathrm{B}=1: 1 ; \tau=5$ мин; $\mathrm{T}=25^{\circ} \mathrm{C}$

Table 3. Germanium extractions with TAMAR depending on the thiocyanate concentration. TAMAR Aqueous phase: $1.93 \cdot 10^{-3} \mathrm{M} \mathrm{Ge}+1,0 \mathrm{M} \mathrm{H}_{2} \mathrm{SO}_{4}+\mathrm{NH}_{4} \mathrm{CNS}$. Extraction conditions: $\mathrm{O}: \mathrm{B}=1: 1 ; \tau=5 \mathrm{~min} ; \mathrm{T}=25^{\circ} \mathrm{C}$

\begin{tabular}{|c|c|c|c|c|}
\hline $\mathrm{NH}_{4} \mathrm{CNS}_{\text {(исх.) }}, \mathrm{M}$ & $\mathrm{D}_{\mathrm{Ge}}$ & $\mathrm{CNS}_{(\mathrm{s})}, \mathrm{M}$ & $\mathrm{CNS}_{(\text {) })} ; \mathrm{M}$ & $\mathrm{CNS}_{(\text {()) }}: \mathrm{R}_{4} \mathrm{~N}_{(\mathrm{o})}, \mathrm{M}: \mathrm{M}$ \\
\hline 0,0 & 0,0 & 0,04 & 0,88 & 1,76 \\
\hline 0,26 & 1,03 & 0,17 & 1,01 & 2,02 \\
\hline 0,43 & 1,92 & 0,25 & 1,1 & 2,2 \\
\hline 0,85 & 7,75 & 0,65 & 1,12 & 2,24 \\
\hline
\end{tabular}

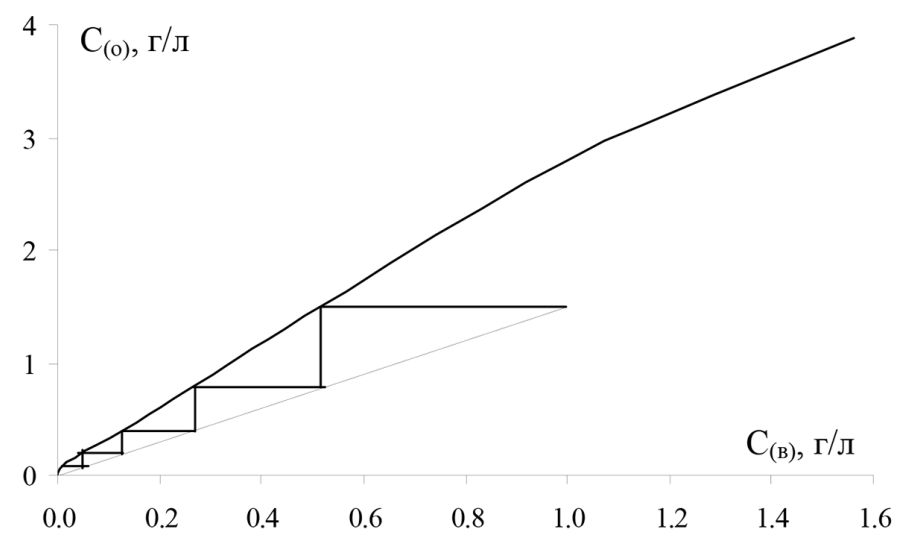

Рис. 4. Изотерма экстракции германия. Экстрагент: 0,5 М ТАМАР в керосине +20 \% 2-этилгексанола. Водная фаза: $\mathrm{Ge}+1,0 \mathrm{M} \mathrm{H}_{2} \mathrm{SO}_{4}+1,0 \mathrm{M} \mathrm{NH}_{4} \mathrm{CNS}$. Условия экстракции: $\tau=5$ мин, $\mathrm{T}=25^{\circ} \mathrm{C}$

Fig. 4. Germanium extraction isotherm. Extractant: 0.5 M TAMAR in kerosene $+20 \%$ 2-ethylhexanol. Aqueous phase: $\mathrm{Ge}+1,0 \mathrm{M} \mathrm{H}_{2} \mathrm{SO}_{4}+1,0 \mathrm{M} \mathrm{NH}_{4} \mathrm{CNS}$. Extraction conditions: $\tau=5 \mathrm{~min}, \mathrm{~T}=25^{\circ} \mathrm{C}$

На рис. 4 приведена изотерма экстракции германия из сернокисло-роданидных растворов TAMАР. Видно, что за 5-6 ступеней экстракции при В:О = 1,5 :1 при исходном содержании германия 1,0 г/л в водной фазе можно извлечь германий до его остаточного содержания 0,005 г/л, т.е. степень извлечения составляет 99,5\%.

Реэкстракция германия из экстрактов с ТАМАР может быть достаточно просто осуществлена щелочными растворами. Так, при обработке экстрагента (0,5 моль/л ТАМАР в керосине +20 \% 2-этилгексанола), содержащего 2,0 г/л $\mathrm{Ge}$, раствором 2,4 $\mathrm{M} \mathrm{NH}_{4} \mathrm{OH}$ при O:B = 2,6:1 германий реэкстрагировался практически полностью, в водной фазе обнаружено 5,2 г/л $\mathrm{Ge}$, в органической фазе не обнаружено.

\section{Выводы}

Изучена экстракция $\mathrm{Ge}$ из сернокислых растворов различными экстрагентами (фосфорорганическими и монокарбоновыми кислотами, органическими аминами и др.) в присутствии роданид-иона. Во всех случаях наблюдается заметное увеличение экстракции по сравнению с экстракцией из сернокислых растворов. 
В системах с Cуanex 301 в присутствии CNS-иона наблюдается существенное увеличение экстракции $\mathrm{Ge}$, в связи с этим для извлечения $\mathrm{Ge}$ достаточно использовать экстрагент с концентрацией 0,1-0,15 моль/л.

Показано, что TAMAP также может эффективно извлекать Ge из сернокислых роданидных растворов. За 5-6 ступеней экстракции 0,5 М раствором ТАМАР в растворителе извлечение Ge составило 99,5\%.

Использование экстракционных систем на основе Суаnex 301 и ТАМАР в присутствии CNS-иона позволяет отказаться от таких дорогих экстрагентов, как Kelex 100 и Lix 63, и представляет несомненный практический интерес для гидрометаллургических процессов извлечения германия.

\section{Благодарности / Acknowledgements}

Работа выполнена в рамках государственного задания Института химии и химической технологии СО РАН (проект АААА-А17-117021310220-0) с использованием оборудования Красноярского регионального центра коллективного пользования ФИЦ КНЦ СО РАН.

This work was conducted within the framework of the budget project AAAA-A17-117021310220-0 for Institute of Chemistry and Chemical Technology SB RAS using the equipment of Krasnoyarsk Regional Research Equipment Centre of SB RAS.

\section{Список литературы / References}

1. Zhang L., Xu Z. One-Pot Synthesis of GeAs Ultrafine Particles from Coal Fly Ash by Vacuum Dynamic Flash Reduction and Inert Gas Condensation. Sci. Rep. 2017. Vol. 7, P. 3641.

2. Kamran H., Irannajad M., Fortuny A., Sastre A.M. Recovery of germanium from leach solutions of fly ash using solvent extraction with various extractants. Hydrometallurgy 2018. Vol. 175, P. 164-169.

3. Большаков К.А. Химия редких и рассеянных элементов. Ч.ІІ. М.: Высшая школа, 1976. 360 c. [Bolshakov K.A. Chemistry of rare and trace elements. Part II. Moscow: Vysshia Shkola, 1976. 360 p. (In Russ.)].

4. Penner L.R., Russell J.H., Campbell M.J. The Role of Extractant Components in the Synergic Extraction of Ge with LIX63/OPAP. Solvent extraction in the process industries. Proceedings of the ISEC '93, UK, York, 1993, 1, P. 1391-1398.

5. Nusen S., Zhu Z., Chairuangsri T., Chuyong C. Recovery of germanium from synthetic leach solution of zinc refinery residues by synergistic solvent extraction using LIX 63 and Ionquest 801. Hydrometallurgy 2015. Vol. 151, P. 122-132.

6. Cheng B., Zhang T., Zhang K., Cao Z., Li Zeng L. Recovery of germanium from acid leach solutions of zinc refineryresidue using an oxime extractant of HBL101. Metallurgical Research Technology 2018. Vol. 115, P. 510-517.

7. Tang S., Zhou C., Jiang X., Zhao C. Extraction separation of germanium with hydroxamic acid HGS98. Journal of Central South University of Technology 2000. Vol. 7(1), P. 40-42.

8. Cote G., Bauer D. Liquid-liquid extraction of germanium with oxine derivatives. Hydrometallurgy 1980. Vol. 5, P. 149-160.

9. Willersinn S. Kinetics of Ge(IV) Extraction Using a Microstructured Membrane Contactor. International Journal of Chemical Kinetics. 2016. Vol. 48 (10), P. 609-621. 
10. Harbuck D.D., Judd J.C., Behunin D.V. Germanium solvent extraction from sulfuric acid solutions (and co-extraction of germanium and gallium). Solvent extraction and ion exchange. 1991. Vol. 9(3), P. 383-401.

11. Haghighi H.K., Irannajad M., Moradkhani D. Facilitated transport of germanium from acidic medium through supported liquid membrane using Cyanex 301 as mobile carrier. Physicochemical Problems of Mineral Processing. 2019. Vol. 55(1), P. 225-236.

12. Liu E., Liu Z., Li Y., Wilson B.P., Lundstrom M. Extraction of Ga and Ge from zinc refinery residues in $\mathrm{H}_{2} \mathrm{C}_{2} \mathrm{O}_{4}$ solutions containing $\mathrm{H}_{2} \mathrm{O}_{2}$. International Journal of Mineral Processing. 2017. P. 14-23.

13. Haghighi H.K., Irannajad M., Fortuny A., Sastre A.M. Recovery of germanium from leach solutions of fly ash using solvent extraction with various extractants. Hydrometallurgy. 2018. Vol. 175, P. 164-169.

14. Zhang T., Jiang T., Liu Z. Recovery of Ge(IV) from synthetic leaching solution of secondary zinc oxide by solvent extraction using tertiary amine (N235) as extractant and trioctyl phosphate (TOP) as modifier. Minerals Engineering. 2019. Vol. 136(1), P. 155-160.

15. Патент 2363749 RU. Пашков Г.Л., Флейтлих И.Ю., Григорьева Н.А., Никифорова Л.К. Способ извлечения германия из растворов. Опубл. 10.08.2009. [Patent 2363749 RU. Pashkov G.L., Fleitlikh I.Yu., Grigorieva N.A., Nikiforova L.K. Method of germanium extraction from solutions. Publ. Date 10.08.2009 (In Russ.)].

16. Золотов Ю.А. Экстракция внутрикомплексных соединений. М.: Наука, 1968. 295 с. [Zolotov Yu.A. Extraction of intracomplex compounds. Moscow: Nauka, 1968. 295 p. (In Russ.)].

17. Шмидт В.С. Экстракция аминами. М.: Атомиздат, 1980. 264 c. [Schmidt V.S. Extraction with amines. Moscow: Atomizdat, 1980. 264 p. (In Russ.)].

18. Рахманько Е.М., Матвейчук Ю.В., Качанович И.В. Роданидные комплексы металлов в экстракции и ионометрии. Минск: БГУ, 2017. 171 с. [Rakhman'ko E.M., Matveychuk Yu.V., Kachanovich I.V. Thiocyanate complexesof metals in extraction and ionometry. Minsk: BFU, 2017. 171 p. (In Russ.)].

19. Назаренко В.А. Аналитическая химия германия. М.: Наука, 1973. 264 с. [Nazarenko V.A. Analytical chemistry of germanium. Moscow: Nauka, 1973. 264 p. (In Russ.)]. 